\title{
Article \\ Oxidation of Terpenoids to Achieve High-Value Flavor and Fragrances-Questioning Microalgae Oxidative Capabilities in the Biotransformation of the Sesquiterpene Valencene and of Selected Natural Apocarotenoids
}

\author{
Davide De Simeis ${ }^{1, *(0)}$, Stefano Serra ${ }^{1}\left(\mathbb{D}\right.$, Alessandro Di Fonzo ${ }^{2}\left(\mathbb{D}\right.$ and Francesco Secundo ${ }^{2}(\mathbb{D}$ \\ 1 Consiglio Nazionale delle Ricerche (C.N.R.), Istituto di Scienze e Tecnologie Chimiche, Via Mancinelli 7 , \\ 20131 Milano, Italy; stefano.serra@cnr.it \\ 2 Consiglio Nazionale delle Ricerche (C.N.R.), Istituto di Scienze e Tecnologie Chimiche, Via Mario Bianco 9, \\ 20131 Milan, Italy; ale.difo93@gmail.com (A.D.F.); francesco.secundo@cnr.it (F.S.) \\ * Correspondence: dav.biotec01@gmail.com
}

\section{check for}

updates

Citation: De Simeis, D.; Serra, S.; Di Fonzo, A.; Secundo, F. Oxidation of Terpenoids to Achieve High-Value Flavor and Fragrances-Questioning Microalgae Oxidative Capabilities in the Biotransformation of the Sesquiterpene Valencene and of Selected Natural Apocarotenoids. Chemistry 2021, 3, 821-830. https:/ / doi.org/10.3390/chemistry3030059

Academic Editor: Luca Forti

Received: 23 May 2021

Accepted: 26 July 2021

Published: 28 July 2021

Publisher's Note: MDPI stays neutral with regard to jurisdictional claims in published maps and institutional affiliations.

Copyright: (c) 2021 by the authors. Licensee MDPI, Basel, Switzerland. This article is an open access article distributed under the terms and conditions of the Creative Commons Attribution (CC BY) license (https:/ / creativecommons.org/licenses/by/ $4.0 /)$.

\begin{abstract}
Natural flavor and fragrance market size is expected to grow steadily due to the rising consumer demand of natural ingredients. This market request is guided by the general opinion that the production of natural compounds leads to a reduction of pollution, with inherent advantages for the environment and people's health. The biotransformation reactions have gained high relevance in the production of natural products. In this context, few pieces of research have described the role of microalgae in the oxidation of terpenoids. In this present study, we questioned the role of microalgal based oxidation in the synthesis of high-value flavors and fragrances. This study investigated the role of three different microalgae strains, Chlorella sp. (211.8b and 211.8p) and Chlorococcum sp. (JB3), in the oxidation of different terpenoid substrates: $\alpha$-ionone, $\beta$-ionone, theaspirane and valencene. Unfortunately, the experimental data showed that the microalgal strains used are not responsible for the substrate oxidation. In fact, our experiments demonstrate that the transformation of the four starting compounds is a photochemical reaction that involves the oxygen as oxidant. Even though these findings cast a shadow on the use of these microorganisms for an industrial purpose, they open a new possible strategy to easily obtain nootkatone in a natural way by just using an aqueous medium, oxygen and light.
\end{abstract}

Keywords: microalgae; oxidation; terpenes; flavors; fragrances; nootkatone

\section{Introduction}

The necessity to achieve high value products through natural and generally recognized as safe methods is becoming crucial for the flavor and fragrances market sector [1,2]. In the European Union (EU), natural flavors are defined in regulation (EC) 1334/2008. This regulation defines as natural substances (i) derived from material of vegetable, animal, or microbiological origin; (ii) obtained by appropriate physical, enzymatic or microbiological processes; and (iii) naturally occurring and identifiable in nature. Moreover, the EU requires that natural flavors be manufactured only by traditional food preparation processes such as heating/cooking, grinding, cutting or pressing. So far, it is possible to use processes involving microorganisms and enzymes as catalysts, considering them to be good candidates and substitutes for synthetic and inorganic catalysts in manufacturing natural flavors. These restrictions have different outcomes referable principally in an overall increase of the manufacturing process and final product costs.

In this present study, we focused our attention on the oxidation of the terpenoids valencene (1), $\alpha$-ionone (2), $\beta$-ionone (3) and theaspirane (4), to produce derivatives of huge interest in the flavor and fragrances industry. Ionone and theaspirane, composed of thirteen carbon atoms, are natural organic molecules derived from carotenoid degradation either 
through chemical/physical mechanisms or through enzyme(s)-catalyzed reactions [3,4]. These are relevant flavors or fragrances, and their accessibility represents an important economic resource for chemical companies [4]. As mentioned above, their market value is not only related to the manufacturing cost. Indeed, the consumers' preference creates two different markets for the same chemical compound depending on its origin. In fact, the possibility to classify the product as artificial or natural influences its final cost.

For example, natural $\alpha$-ionone could cost up to $1400 € / \mathrm{Kg}$, while synthetic $\alpha$-ionone costs $200 € / \mathrm{Kg}$. Moreover, from a single oxidation step, the economic earn could be exponential. Actually, the principal result of the introduction of a hydroxy- or ketofunctional group in compounds $\mathbf{1 - 4}$ is a decrease in volatility and an increase in the odor persistence. Another notable example in this case is natural nootkatone (sold up to $7500 € / \mathrm{Kg}$ ), one of the most important and expensive aromatics of grapefruit, deriving from the oxidation of natural 1 (sold around $700 € / \mathrm{Kg}$ ) (Figure 1).<smiles>C=C(C)C1CCC2=CCCC[C@H]2C1C</smiles>

natural valencene

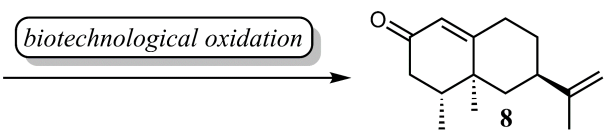

natural nootkatone

Figure 1. Single oxidation obtaining natural nootkatone (8) starting from natural valencene (1).

The oxidation products derived from compounds $2-\mathbf{4}$ were found to be components of different natural flavors such as saffron, tobacco and black tea [5] (Figure 2).

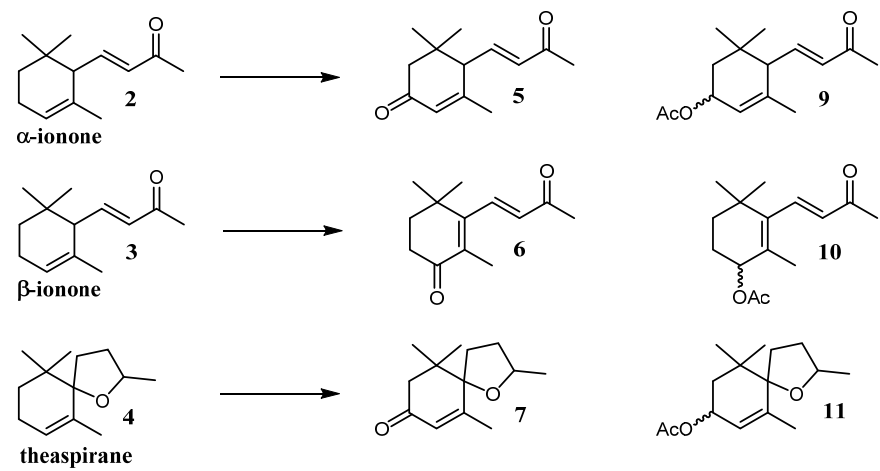

Figure 2. Oxidation products derived from $\alpha$-ionone (2), $\beta$-ionone (3), and theaspirane (4) named 3 -keto- $\alpha$-ionone (5); 3 -acetoxy- $\alpha$-ionone (9); 4 -keto- $\beta$-ionone (6); 4 -Acetoxy- $\beta$-ionone (10); theaspirane (7) and 3-acetoxy-theaspirane (11), respectively.

The interest in studying microalgae biology is soaring fast in recent years. These microorganisms are easy to use as biocatalysts, can be grown autotrophically, and possess enzymatic activities that can be exploited in different fields such as biorefinery, bioremediation and biocatalysis [6-8]. Moreover, these microorganisms are largely studied as cell factories of metabolites, useful in different commercial sectors such as nutraceuticals, food supplements, colorants and agriculture [9-11], but less is known about their enzymatic activities and their use in biotransformations applied to flavor and fragrances [12-14].

We decided to evaluate their ability in the transformation of terpenoids due to their intrinsic capability to metabolize isoprenic units. In fact, several algal and cyanobacterial species can produce terpenoids as secondary metabolites.

Among algae, Rhodophyta phylum is the richest source of secondary metabolites, with many genera known for their ability to produce terpenoids [15]. In the case of cyanobacteria, genes encoding the enzymes involved in the terpenoid biosynthetic pathway were identified in different species belonging to different terrestrial or marine environments [16]. Microalgae can also produce complex derivatives of terpenes such as alpha and betacarotene, lutein, lycopene, astaxanthin and zeaxanthin. These carotenoids' biosynthesis is associated with light harvesting, protein assembly in photosystems, and protection against photo-induced free radical exposure [17]. 
Bio-based processes aimed at the transformation of terpenoids allows the preparation of high-value molecules using inexpensive raw materials. In addition, the reactions are performed in mild and ecofriendly conditions, complying with the EU current regulations concerning the natural classification.

Such a high market value has induced numerous research groups to develop different biotechnological processes for the synthesis of these high value compounds based on the biotransformation by bacterial, fungal or plant species [18-20]. However, nowadays a unique and reliable bio-based method to achieve oxidized terpenoids useful for an industrial purpose does not exist.

Photoautotrophic microorganisms can perform many regio and diastereoselective reactions on terpenes and different examples were reported in literature. An example of selective bioreduction of monoterpenes is the biotransformation of both isomers of carvone. Shimoda et al. in 2004 showed that $(R)-(-)$-carvone (12) and $(S)-(+)$-carvone (13) were reduced after 3 days of incubation by Synechococcus sp. PCC 7942 to $(1 S, 4 R)-$ dihydrocarvone (14) and (1S,4S)-dihydrocarvone (15), respectively, with a high yield (99\%) (Figure 3) [21,22].
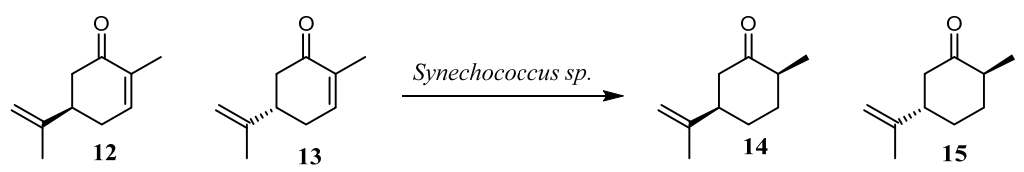

Figure 3. $(R)-(-)$-carvone and (S)-(+)-carvone reduction after 3 days of incubation by Synechococcus sp. PCC 7942 to $(1 S, 4 R)$-dihydrocarvone and $(1 S, 4 S)$-dihydrocarvone.

It is worth noting that different studies described the microalgae-catalyzed oxidation of valencene to afford nootkatone in good yields [23-25]. After the publication of these studies, no further groups investigated the microalgae-mediated oxidation of valencene. Since we are involved in a research project aimed at the biocatalytic production of high value flavors, we undertook a related study, investigating the biotransformation of natural compounds 1-4 by the action of three different microalgae strains. Nevertheless, our study led to a completely different conclusion, because all the microalgae we tested did not play any role in the formation of the oxidation products. Therefore, only the combined action of oxygen, light and aqueous medium is responsible for the investigated oxidation reactions.

The possibility to achieve high value natural terpenoids through simply mixing the natural substrates in an aqueous medium in presence of air and under sunlight irradiation, can be regarded as an intrinsically green oxidation process. This could permit us to overcome several issues related to manufacturing costs, also allowing industries to streamline their production processes.

\section{Materials and Methods}

\subsection{Chemicals}

All solvents and reagents were of commercial quality and were purchased from SigmaAldrich (St. Louis, MO, USA). Different standards used in this work were synthetized in our laboratory. The keto derivatives: 3 -keto- $\alpha$-ionone (5), 4-keto- $\beta$-ionone (6), theaspirane (7) and nootkatone (8) were prepared by oxidation of $\alpha$-ionone (2), $\beta$-ionone (3), theaspirane (4) and valencene (1). The above described oxidation reactions were performed using TBHP $/ \mathrm{MnO}_{2}$ as oxidant according to our previously reported procedure [26] (purity determined by NMR and GC-analysis after a purification by chromatography and/or distillation). The diastereoisomeric forms of the relative epoxides were prepared by epoxidation of $\alpha$-ionone, theaspirane and $\beta$-ionone using $m$-chloroperbenzoic acid and $\mathrm{CH}_{2} \mathrm{Cl}_{2}$ as solvent (purity determined by NMR and GC-analysis after a purification by chromatography and/or distillation) [5].

Samples of 3-acetoxy- $\alpha$-ionone (9) (2:1 cis / trans mixture) were prepared starting from $\alpha$-ionone according to the procedure described by Tu et al. in 2014 [27]. 4-acetoxy- $\beta$ ionone (10) was prepared starting from 4,5 -epoxy- $\alpha$-ionone by means of $\mathrm{NaOMe}$ mediated 
transposition followed by chemical acetylation $\left(\mathrm{Ac}_{2} \mathrm{O} / \mathrm{Py}\right)$ of the obtained allyl alcohols. 3-acetoxy-theaspirane (mixture of diasteroisomers) (11) was obtained by reduction of the related keto compounds using $\mathrm{NaBH}_{4} / \mathrm{MeOH}$ at $0^{\circ} \mathrm{C}$. The purity of compounds $\mathbf{9 , 1 0}$ and 11 were determined by NMR and GC-analysis after a purification by chromatography and/or distillation.

Purity of the compounds used in this work: (1) $\geq 65 \%$; (2) $\geq 86 \%$; (3) $\geq 95 \%$; (4) $\geq 85 \%$; (5) $\geq 95 \%$; (6) $\geq 95 \%$; (7) $\geq 88 \%$; (8) $\geq 98 \%$; (9) $\geq 92 \%$; (10) $\geq 93 \%$; (11) $\geq 95 \%$.

\subsection{Microalgae Culture}

Two strains of Chlorella sp. (211.8p and 211.8b) and one belonging to the genus of Chlorococcum sp. (JB3) were cultivated in BG-11 medium according to the following experimental conditions. A glycerinated inoculum containing $1.5 \times 10^{8}$ cell $/ \mathrm{mL}$ was added to $40 \mathrm{~mL}$ of BG-11 medium contained in $100 \mathrm{~mL}$ Erlenmeyer flasks. The culture was kept under agitation (120 rpm) at $25{ }^{\circ} \mathrm{C}$ in a thermoshaker (Eppendorf New BrunswickTM Innova 42 incubator) with an illumination of $78 \mu \mathrm{mol} / \mathrm{m}^{2} / \mathrm{s}$ (PCE-170 A Lightmeter). Cycles of light/dark, respectively $16 \mathrm{~h}$ and $8 \mathrm{~h}$, were also performed during culture (15 days).

\subsection{Microalgal Vitality Evaluation}

All of the experiments were performed in triplicate. The vitality of the microalgae of Chlorella sp. (211.8p and 211.8b) and Chlorococcum sp. (JB3), cultivated as described above, was evaluated using $3 \mathrm{~g} / \mathrm{L}$ of 1 and $500 \mathrm{mg} / \mathrm{L}$ of $\mathrm{CuSO}_{4} \cdot 5 \mathrm{H}_{2} \mathrm{O}$ (known algaecide) [28] as a control. Cell vitality assay based on MTT (3-(4,5-dimethylthiazol-2-yl)-2,5-diphenyl tetrazolium bromide was performed at different times. MTT was dissolved in PBS at $5 \mathrm{mg} / \mathrm{mL}$ (stock MTT solution). A sample of $500 \mu \mathrm{L}$ deriving from each flask was mixed with $50 \mu \mathrm{L}$ of the stock MTT solution and incubated at $25^{\circ} \mathrm{C}$ for $4 \mathrm{~h}$.

Then, $500 \mu \mathrm{L}$ of a solution of $\mathrm{HCl}$ in isopropanol $(0.04 \mathrm{M})$ was added to all samples and vortexed in order to dissolve the dark blue crystals. After $2 \mathrm{~min}$ at room temperature, the absorbance of the samples at $590 \mathrm{~nm}$ was measured by the spectrophotometer V-630 UV-VIS (JASCO Deutschland GmbH).

\subsection{Nootkatone Toxicity}

All of the experiments were performed in triplicate. Microalgae strains Chlorella sp. (211.8p and 211.8b) and Chlorococcum sp. (JB3) were inoculated in fresh BG-11 medium $(100 \mathrm{~mL})$ starting from an active culture presenting $3.4 \times 10^{6}$ cell $/ \mathrm{mL}(2 \mathrm{~mL})$. The cultures were kept in culture as described above for 6 days. At this point, $100 \mathrm{mg}$ of nootkatone dissolved in $100 \mu \mathrm{L}$ of DMSO was added to each flask and kept in the same condition (final concentration of nootkatone in flask was $1 \mathrm{~g} / \mathrm{L}$ ). After 3 days, MTT was performed as described above, comparing the results against a control not treated.

\subsection{Biotransformation Experiments and Analysis}

All of the biotransformation experiments were performed in triplicate. An active culture of Chlorella sp. (211.8p and 211.8b) and one belonging to the genus of Chlorococcum sp. (JB3) were cultivated as described above for 10 days. At this time, $2 \mathrm{~mL}\left(3.4 \times 10^{6}\right.$ cell $\left./ \mathrm{mL}\right)$ of the cultures were inoculated in different $100 \mathrm{~mL}$ Erlenmeyer flasks filled with fresh $40 \mathrm{~mL}$ sterile BG-11 medium and left to grow over night. At this point, $3 \mathrm{~g} / \mathrm{L}$ of (1) in DMSO $(150 \mu \mathrm{L})$ previously sterilized by Ministart ${ }^{\circledR}$ Syringe Filter Hydrophilic was added to the culture. In order to exclude both the effect of the light and of the growth medium on the biotransformation, different blank experiments were performed at the same time and conditions. The experimental setting is described in Table 1.

Table 1. Terpenoids moieties ( $3 \mathrm{~g} / \mathrm{L}$ ) oxidized in different experimental conditions.

Experimental Condition 
Table 1. Cont.

\begin{tabular}{ll}
\hline \multicolumn{1}{c}{ Experimental Condition } \\
\hline Dark + Demineralized water \\
\hline Light + BG-11 medium \\
\hline Dark + BG-11 medium \\
\hline Microalgae + Light + BG-11 medium + Glucose \\
\hline Microalgae + Dark + BG-11 medium + Glucose \\
\hline
\end{tabular}

Different microalgae strains can grow as heterotrophs/mixotrophs [29]. For this reason, the cultures grown in the dark were supplemented with $5 \mathrm{~mL}$ of a glucose solution $30 \% w / v$ (final concentration of glucose in the medium was $15 \mathrm{~g} / \mathrm{L}$ ). The biotransformation flasks with valencene were stirred $(120 \mathrm{rpm})$ for 24 days at $25^{\circ} \mathrm{C}$. Then, $3 \mathrm{~g} / \mathrm{L}$ of $2-4$ in DMSO $(150 \mu \mathrm{L})$, previously sterilized by Ministart ${ }^{\circledR}$ Syringe Filter Hydrophilic, were added to 3 different flasks filled with $40 \mathrm{~mL}$ of BG-11 medium and irradiated with a continuous illumination of $78 \mu \mathrm{mol} / \mathrm{m}^{2} / \mathrm{s}$ for 24 days at $25^{\circ} \mathrm{C}$ under agitation $(120 \mathrm{rpm})$.

At this point, the experiments were stopped, the aqueous phases were then extracted three times with ethyl acetate, and the combined organic layers were washed with brine, dried on $\mathrm{Na}_{2} \mathrm{SO}_{4}$, and the solvent was removed under reduced pressure. The crude biotransformation mixtures were then acetylated with pyridine/acetic anhydride $(2 \mathrm{~mL}$ of a 2:1 mixture) and then analyzed by GC-MS.

GC-MS analyses: HP-6890 gas chromatograph equipped with a 5973 mass detector, using a HP-5MS column (30 $\mathrm{m} \times 0.25 \mathrm{~mm}, 0.25 \mu \mathrm{m}$ film thickness; Hewlett Packard) with the following temp. program: $60^{\circ}(1 \mathrm{~min})-6^{\circ} / \mathrm{min}-150^{\circ}(1 \mathrm{~min})-12^{\circ} / \mathrm{min}-280^{\circ}(5 \mathrm{~min})$; carrier gas, He; constant flow 1ml/min; split ratio, 1/30; tr given in min: (5) 20.42; (6) 20.61; (7) 19.02 and 19.19 ; (8) 22.30; (2) 16.23; (3) 17.57 ; (4) 13.40 and 13.77 ; (1) 17.69 ; (9) 21.41 and 21.61; (10) 21.82; (11) 20.17, 20.33, 20.50 and 20.61.

\section{Results}

\subsection{Microalgal Vitality Evaluation and Nootkatone Toxicity}

An MTT assay on JB3; $211.8 \mathrm{~b}$ and 211.8p microalgae species was performed, and the results obtained are shown in Figure 4 (toxicity of valencene in respect to the three different microalgal strains) and Figure 5 (toxicity of nootkatone in respect to the three different microalgal strains).

The vitality assay using valencene was evaluated measuring the absorbance at 590nm of the sample at 4 different times $(0,24,48$ and $72 \mathrm{~h})$ using, as negative control, a wellknown algaecide $\left(\mathrm{CuSO}_{4} \cdot 5 \mathrm{H}_{2} \mathrm{O}\right)$. In the concerned nootkatone, we used the same method measuring directly the 3 rd day of contact considering a slow accumulation of the product during the reaction.

The data are statistically significant ( $p<0.05$, " $t$ " Student test).

\subsection{Biotransformation Experiments}

The biotransformation experiments were carried out in order to understand the role of microalgae in the oxidation of valencene and other terpenes. Table 2 represents the experimental design followed for valencene. In Table 3, we show the effect of the medium BG-11 and light in the absence of microalgae strains concerning the oxidation of compounds $2-4$.

Table 2. Oxidation of valencene $(3 \mathrm{~g} / \mathrm{L})$ in the different experimental conditions. All the value reported in the table are derived from the mathematical average of the different samples related to each other. ${ }^{*}$ The percentage of compound 8 is calculated, integrating the peaks of the chromatogram of the crude mixture.

\begin{tabular}{clcc}
\hline Entry & Experimental Condition & $\begin{array}{c}\text { \% of Compound 8 Found in } \\
\text { Chlorococcum sp. (JB3) }\end{array}$ & $\begin{array}{c}\text { \% of Compound 8 Found in } \\
\text { Chlorella sp. (211.8b) }^{*}\end{array}$ \\
\hline 1 & light + demineralized water & $56 \pm 3$ & $56 \pm 3$ \\
\hline 2 & dark + demineralized water & $17 \pm 2$ & $17 \pm 2$ \\
\hline
\end{tabular}


Table 2. Cont.

\begin{tabular}{|c|c|c|c|c|}
\hline Entry & Experimental Condition & $\begin{array}{l}\% \text { of Compound } 8 \text { Found in } \\
\text { Chlorococcum sp. (JB3) }\end{array}$ & $\begin{array}{l}\text { \% of Compound } 8 \text { Found in } \\
\text { Chlorella sp. }(211.8 b) *\end{array}$ & $\begin{array}{l}\% \text { of Compound } 8 \text { Found in } \\
\text { Chlorella sp. }(211.8 \mathrm{p})^{*}\end{array}$ \\
\hline 3 & light + BG-11 medium & $50 \pm 5$ & $50 \pm 5$ & $50 \pm 5$ \\
\hline 4 & dark + BG-11 medium & $20 \pm 2$ & $20 \pm 2$ & $20 \pm 2$ \\
\hline 5 & $\begin{aligned} \text { microalgae } & + \text { light }+ \text { BG-11 medium } \\
& + \text { glucose }\end{aligned}$ & $61 \pm 3$ & $58 \pm 5$ & $64 \pm 3$ \\
\hline 6 & $\begin{aligned} \text { microalgae } & + \text { dark }+ \text { BG-11 medium } \\
& + \text { glucose }\end{aligned}$ & $8 \pm 1$ & $10 \pm 2$ & $7 \pm 1$ \\
\hline
\end{tabular}
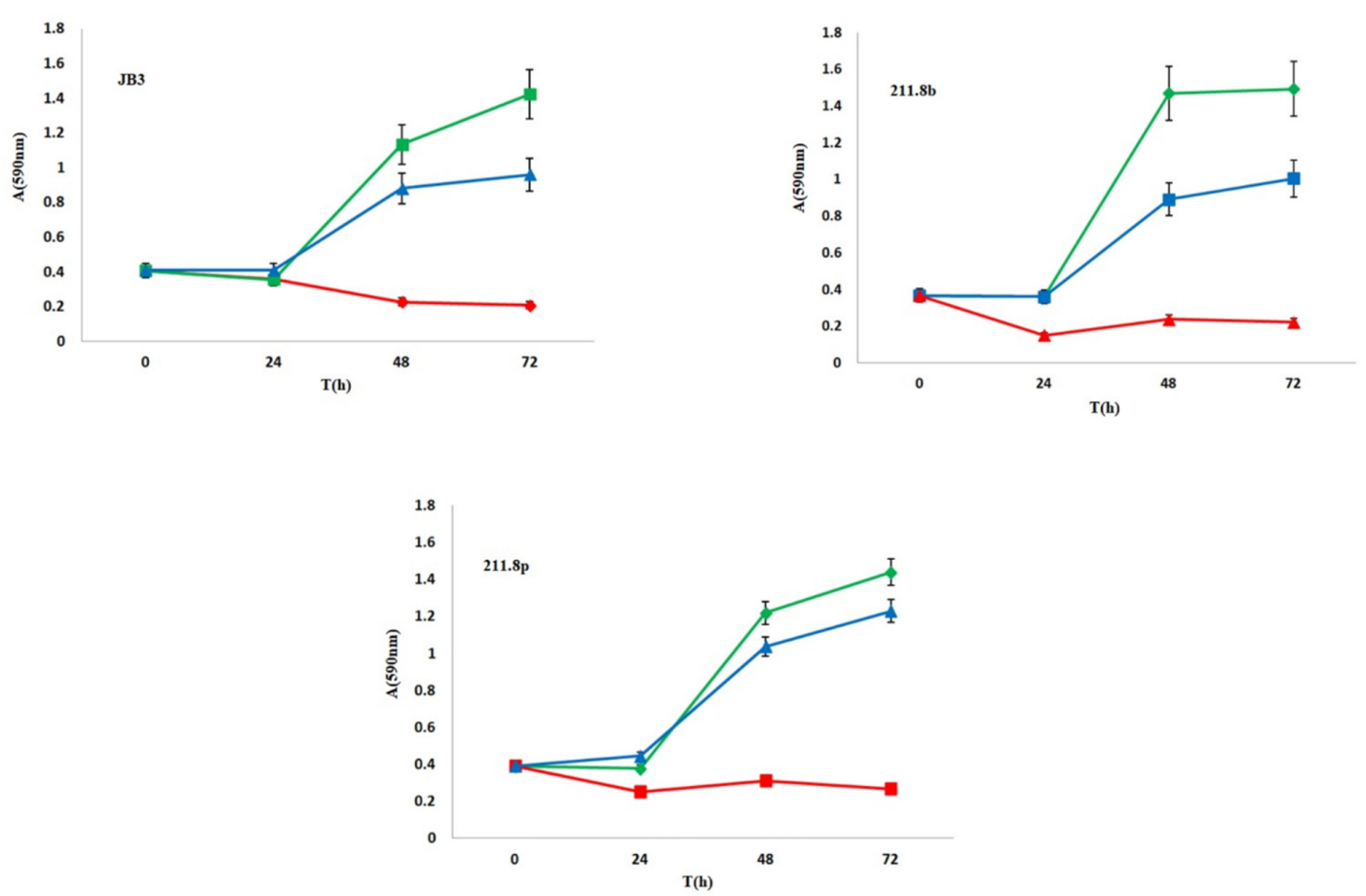

Figure 4. MTT assay on JB3; 211.8b and 211.8p microalgae species. Absorbance at $590 \mathrm{~nm}$ is a time function expressed in hours. The green line represents the positive control (not treated); blue line represents microalgae + valencene $(3 \mathrm{~g} / \mathrm{L})$; red line represents microalgae $+\mathrm{CuSO}_{4} \cdot 5 \mathrm{H}_{2} \mathrm{O}(500 \mathrm{mg} / \mathrm{L})$.

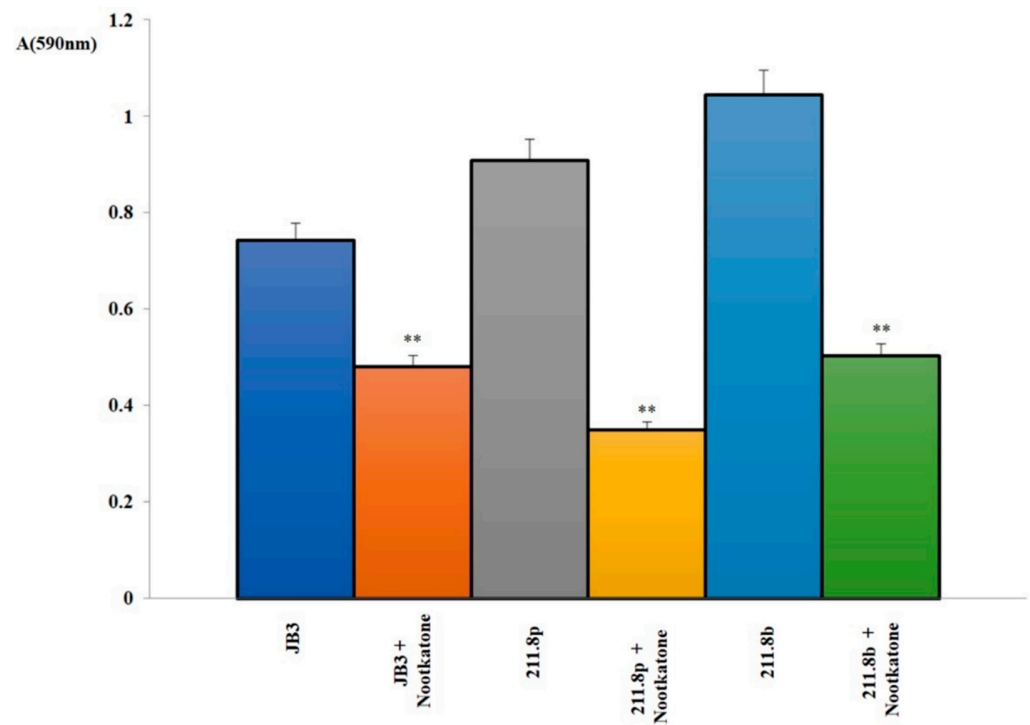

Figure 5. MTT assay performed on the 3 different species of the investigated microalgae either not treated or after treatment with nootkatone $(1 \mathrm{~g} / \mathrm{L}, 3$ days). The samples were analyzed at $590 \mathrm{~nm}$. ** $p<0.05$. 
Table 3. Oxidation of substrates 2-4 (3 g/L) in BG-11 medium with a continuous illumination of $78 \mu \mathrm{mol} / \mathrm{m} 2 / \mathrm{s}$. * All the value reported in the table are derived from the mathematical average of three different samples integrating the peaks of the chromatogram of the crude mixture.

\begin{tabular}{|c|c|c|c|c|c|}
\hline Entry & $\begin{array}{l}\text { Experimental } \\
\text { Condition }\end{array}$ & Substrate & Compound Observed & $\begin{array}{l}\% \text { Observed in the Crude } \\
\text { Mixture }\end{array}$ & $\begin{array}{l}\text { Oxidation Products Observed in the } \\
\text { Crude Mixture (\%)* }\end{array}$ \\
\hline \multirow{2}{*}{ A } & \multirow{2}{*}{$\begin{array}{l}\text { light }+ \text { BG-11 } \\
\text { medium }\end{array}$} & \multirow{2}{*}{ Theaspirane } & 7 & 7 & \multirow{2}{*}{82} \\
\hline & & & 11 & 3 & \\
\hline \multirow{2}{*}{ B } & \multirow{2}{*}{$\begin{array}{l}\text { light }+ \text { BG-11 } \\
\text { medium }\end{array}$} & \multirow{2}{*}{$\beta$-ionone } & 6 & 2 & \multirow{2}{*}{86} \\
\hline & & & 10 & - & \\
\hline \multirow{2}{*}{$\mathrm{C}$} & \multirow{2}{*}{$\begin{array}{l}\text { light }+ \text { BG-11 } \\
\text { medium }\end{array}$} & \multirow{2}{*}{$\alpha$-ionone } & 5 & 1 & \multirow{2}{*}{80} \\
\hline & & & 9 & 3 & \\
\hline
\end{tabular}

\section{Discussion}

In this work we evaluated the activity of two strains of Chlorella sp. (211.8p and 211.8b) and a species of Chlorococcum sp. (JB3). The coccoid green microalgae genus Chlorella is one of the most important commercial microalgae for food nutrition [30]. In the European Union, microalgae trading is regulated under the Novel Food Regulation (EC) No. 258/97 which states that foods or food ingredients that have not been used for human consumption to a significant degree in the EU before 15 May 1997 require a safety assessment. Since the Chlorella genus is widely used as a food supplement worldwide and few safety concerns are related to their use [31], we decided to use this alga in our study. Concerning the genus Chlorococcum, it was recognized as a promising commercial source of ketocarotenoids due to its relatively fast growth rate and its versatility to also grow easily in outdoor-stressed conditions [32,33]. Moreover, it was recognized that the Chlorococcum genus can synthesize astaxanthin from $\beta$-carotene through various pathways which are different from other astaxanthin producing microorganisms [34]. Therefore, considering an enzymatic supply able to metabolize carotenoids, we decide to use the Chlorococcum genus in this study, which also investigates apocarotenoid oxidation.

In order to understand the toxicity effects of the substrate 1, we used the colorimetric MTT assay for assessing cell metabolic activity. This technology is often used for mammalian cells and only rarely for microalgae. Nevertheless, MTT efficacy was also well demonstrated for these microorganisms [35].

The MTT assay exploits the yellow tetrazolium salt 3-(4,5-dimethylthiazol-2-yl)-2,5diphenyltetrazolium bromide as an indicator. In living cells, this tetrazole salt is reduced by oxo-reductive enzyme(s) of the cell respiratory chain in an insoluble purple formazan product that is quantifiable by spectrophotometry [36].

The assay was performed comparing the sample vitality with those of a sample treated with $\mathrm{CuSO}_{4} \cdot 5 \mathrm{H}_{2} \mathrm{O}$ as algaecide (negative control) and an active growing culture (positive control). The data showed that substrate 1 at $3 \mathrm{~g} / \mathrm{L}$ did not possess significant inhibitory activity against microalgae cultures compared with the positive control $(p>0.05$, " $t$ " Student test) (Figure 4).

We have also evaluated the toxicity of nootkatone to understand the potential of these microorganisms for an applicative use for flavor and fragrance industries.

Unfortunately, these particular strains are not able to tolerate high levels of nootkatone in the medium. In fact, data reported in Figure 5 demonstrated that $1 \mathrm{~g} / \mathrm{L}$ of nootkatone is toxic for all the three strains used ( $p<0.05$, " $t$ " Student test).

It is known that terpenes containing unsaturated moieties are prone to oxidation. Microbial media are complex matrixes useful for microbial growth, and different elements present in them could contribute to catalyzing oxidation reactions. The data obtained have shown that the valencene conversion in $\mathbf{8}$ is principally mediated by light and oxygen. In fact, using demineralized water in the presence of light, valencene is converted in nootkatone in considerable amounts (56\%). BG-11 medium seems to have a marginal role in this kind of transformation. In fact, the rate of conversion of valencene in the absence of light is very similar both using BG-11 medium or demineralized water $(\approx 20 \%)$. BG-11 
medium is made up of sodium nitrate as its main component, and metal salts in trace amounts. Our experiments, performed using demineralized water, completely exclude the possibility that the nitrate anion could play the role of oxidant. The role of the metal salts could not be excluded; even our result did not confirm their involvement in the oxidation reactions. Indeed, it is important to consider that some transition metals could be involved as catalysts in this process. From a chemical point view, nootkatone is obtained from valencene using strong oxidant-like tert-butyl peracetate, chromium salts or peroxide generating reagents [25,37]. Moreover, Hong et al. (2016) have proposed a mechanism in which the dehydration of an allylic hydroperoxides into the corresponding enone is catalyzed by Lewis acids such as $\mathrm{Cu}^{2+}, \mathrm{Co}^{2+}, \mathrm{Mn}^{2+}$ or $\mathrm{Mo}^{6+}$ salts [38]. In this mechanism, the coordination of the metal with the peroxide has been considered to weaken the $\mathrm{O}-\mathrm{O}$ bond and, accordingly, facilitates the dehydration.

The role of oxygen seems to be elucidated using microalgal cultures. When microalgae are grown in the absence of light using glucose as a carbon source, the yield of nootkatone decrease to $10 \%$. The reason for this result could be attributed to the consumption of oxygen mediated by microalgae during the reaction. Otherwise, in the presence of light, photosynthesis is restored and the consumption of oxygen by microalgae is balanced between a heterotrophic and autotrophic behavior. This permits the reaction to proceed comparably to the control condition in which demineralized water and light is used.

Two possible oxidation mechanisms are described in Figure 6. According to the results of Table 2, the presence of oxygen is essential to achieve valencene oxidation (entry 6). In this experiment, microalgae consumed oxygen to sustain their metabolism and, as a result, the transformation yield dwindled dramatically. In addition, the transformation yields are greatly improved by light, as demonstrated by the low yield obtained in entries 2 and 4 .

The first mechanism could proceed through a type I photooxygenation involving triplet oxygen. According to our reasoning, the light could activate a sensitizer (maybe present as an impurity of the substrate) that could generate radical species (16) from substrate 1. The following reaction with triplet oxygen could lead to the radical (17) and then to the hydroperoxide (18). The decomposition of allyl hydroperoxides can proceed both spontaneously or catalytically to give the corresponding ketones and water [26]. The second mechanism involves singlet oxygen, which leads to an "ene-reaction" (Schenck ene reaction) [39] affording the two hydroperoxides 19 and 20. According to previous works [38,39], only the tertiary hydroperoxide 20 can rearrange to give compound $\mathbf{1 8}$, which finally affords nootkatone 8 . Taking in account that in our experiments we didn't detected nootkatone isomers deriving from hydroperoxide 19, we suppose that the oxidation reaction follows the first path (type I photooxygenation)

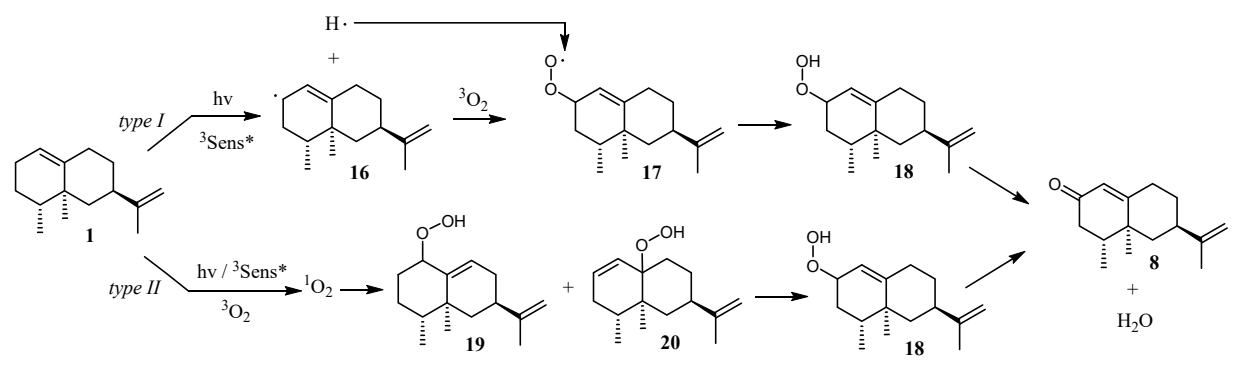

Figure 6. Proposed photooxidation mechanisms of valencene (1) to obtain nootkatone (8).

In the absence of light, the yield decreased (Table 2, entry 2 and 4) although with minor nootkatone formation. We assume the radical chain oxidation process does not stop completely, even in the dark, because of the thermal generation of radical initiators.

Preliminary experiments using $\mathbf{2 - 4}$ as substrates put doubts on the real capability of microalgae to perform oxidative biotransformations. The above-described findings suggested that we analyze the oxidation of substrates $\mathbf{2 - 4}$ in BG-11 medium without microalgae. We conceived an experiment in which 2-4 were allowed to react in BG-11 
medium with a continuous illumination (Table 3), demonstrating unambiguously that the oxidation was not biocatalyzed.

The reactivity observed for valencene could be extended to the other apocarotenoids tested. In fact, even though the identified products are fewer compared to the total number of oxidation products found in the crude mixture, the starting materials are almost completely converted in a plethora of oxidized products.

\section{Conclusions}

This study showed the importance of the light and of the oxygen in the oxidation of these terpenoid compounds. Even though other researchers demonstrated that microalgae belonging to the genus Chlorella can oxidize valencene to nootkatone, our study did not confirm these findings. These differences from literature could be related to specific genetic traits of the strains used in the other works, but the main actors involved in this kind of transformation seem to be light and oxygen without any involvement of the micro-algal enzymatic set present in or outside the cell. Even though microalgae seem not to be involved in this kind of oxidation, we opened a path in which natural odorous compounds derived from simple terpenes or apocarotenoids could be obtained easily, only taking advantage of light, oxygen and water. Such conceived chemical processes could allow the performance of oxidation whilst reducing the use of toxic catalysts, solvents and reagents in favor of an eco-friendly and natural approach. Further studies should be conducted to find the optimal reaction conditions in terms of oxygen concentration, light exposure and temperature. In addition, it is worth noting that our study raises the issue of the reliability of the previous studies involving the use of microalgae in oxidative biotransformations.

Author Contributions: Conceptualization, D.D.S. and S.S.; formal analysis, A.D.F., D.D.S. and S.S.; writing-original draft preparation, D.D.S.; writing-review and editing, S.S.; visualization, F.S.; supervision, S.S. All authors have read and agreed to the published version of the manuscript.

Funding: This research was founded by Regione Lombardia project PORFESR 2014-2020 n. 228775 VIPCAT (Value Added Innovative Protocols for Catalytic Transformations).

Data Availability Statement: Not applicable.

Acknowledgments: The authors thank Regione Lombardia for supporting this study within the project PORFESR 2014-2020 n. 228775 VIPCAT (Value Added Innovative Protocols for Catalytic Transformations).

Conflicts of Interest: The authors declare no conflict of interest.

\section{References}

1. Pandal, N. Global Markets for Flavors and Fragrances; BCC Research: Wellesley, MA, USA, 2014.

2. Van Wyk, N.; Kroukamp, H.; Pretorius, I.S. The smell of synthetic biology: Engineering strategies for aroma compound pro-duction in yeast. Fermentation 2018, 4, 54. [CrossRef]

3. Serra, S. Recent Advances in the Synthesis of Carotenoid-Derived Flavours and Fragrances. Molecules 2015, 20, 12817-12840. [CrossRef] [PubMed]

4. Harrison, P.J.; Bugg, T.D. Enzymology of the carotenoid cleavage dioxygenases: Reaction mechanisms, inhibition and biochemical roles. Arch. Biochem. Biophys. 2014, 544, 105-111. [CrossRef] [PubMed]

5. Serra, S.; De Simeis, D. Fungi-Mediated Biotransformation of the Isomeric Forms of the Apocarotenoids Ionone, Damascone and Theaspirane. Molecules 2019, 24, 19. [CrossRef]

6. Lee, X.J.; Ong, H.C.; Gan, Y.Y.; Chen, W.-H.; Mahlia, T.M.I. State of art review on conventional and advanced pyrolysis of macroalgae and microalgae for biochar, bio-oil and bio-syngas production. Energy Convers. Manag. 2020, 210, 112707. [CrossRef]

7. Chen, H.; Wang, Q. Microalgae-based nitrogen bioremediation. Algal Res. 2020, 46, 101775. [CrossRef]

8. Della Greca, M.; Pinto, G.; Pistillo, P.; Pollio, A.; Previtera, L.; Temussi, F. Biotransformation of ethinylestradiol by microalgae. Chemosphere 2008, 70, 2047-2053. [CrossRef]

9. Odjadjare, E.C.; Mutanda, T.; Olaniran, A.O. Potential biotechnological application of microalgae: A critical review. Crit. Rev. Biotechnol. 2017, 37, 37-52. [CrossRef]

10. Mathimani, T.; Baldinelli, A.; Rajendran, K.; Prabakar, D.; Matheswaran, M.; van Leeuwen, R.P.; Pugazhendhi, A. Review on cultivation and thermochemical conversion of microalgae to fuels and chemicals: Process evaluation and knowledge gaps. $J$. Clean. Prod. 2019, 208, 1053-1064. [CrossRef] 
11. Pavela, R.; Benelli, G. Essential Oils as Ecofriendly Biopesticides? Challenges and Constraints. Trends Plant Sci. 2016, 21, $1000-1007$. [CrossRef]

12. Rasoul-Amini, S.; Fotooh-Abadi, E.; Ghasemi, Y. Biotransformation of monoterpenes by immobilized microalgae. Environ. Boil. Fishes 2011, 23, 975-981. [CrossRef]

13. Tripathi, U.; Rao, S.R.; Ravishankar, G. Biotransformation of phenylpropanoid compounds to vanilla flavor metabolites in cul-tures of Haematococcus pluvialis. Process Biochem. 2002, 38, 419-426. [CrossRef]

14. De Carvalho, C.C.; da Fonseca, M.M.R. Biotransformation of terpenes. Biotechnol. Adv. 2006, 24, 134-142. [CrossRef] [PubMed]

15. Wei, G.; Jia, Q.; Chen, X.; Köllner, T.G.; Bhattacharya, D.; Wong, G.K.-S.; Gershenzon, J.; Chen, F. Terpene Biosynthesis in Red Algae Is Catalyzed by Microbial Type But Not Typical Plant Terpene Synthases. Plant Physiol. 2019, 179, 382-390. [CrossRef] [PubMed]

16. Pattanaik, B.; Lindberg, P. Terpenoids and Their Biosynthesis in Cyanobacteria. Life 2015, 5, 269-293. [CrossRef]

17. Gonçalves, A.L. The use of microalgae and cyanobacteria in the improvement of agricultural practices: A review on their biofertilising, biostimulating and biopesticide roles. Appl. Sci. 2021, 11, 871. [CrossRef]

18. Lee, J.-W.; Trinh, C.T. Towards renewable flavors, fragrances, and beyond. Curr. Opin. Biotechnol. 2020, 61, 168-180. [CrossRef]

19. Janssens, L.; De Pooter, H.; Schamp, N.; Vandamme, E. Production of flavors by microorganisms. Process Biochem. 1992, 27, 195-215. [CrossRef]

20. Fraatz, M.A.; Berger, R.G.; Zorn, H. Nootkatone-A biotechnological challenge. Appl. Microbiol. Biotechnol. $2009,83,35-41$. [CrossRef]

21. Shimoda, K.; Kubota, N.; Hamada, H.; Kaji, M.; Hirata, T. Asymmetric reduction of enones with Synechococcus sp. PCC 7942. Tetrahedron Asymmetry 2004, 15, 1677-1679. [CrossRef]

22. Balcerzak, L.; Lipok, J.; Strub, D.; Lochyński, S. Biotransformations of monoterpenes by photoautotrophic micro-organisms. J. Appl. Microbiol. 2014, 117, 1523-1536. [CrossRef]

23. Furusawa, M.; Hashimoto, T.; Noma, Y.; Asakawa, Y. Highly Efficient Production of Nootkatone, the Grapefruit Aroma from Valencene, by Biotransformation. Chem. Pharm. Bull. 2005, 53, 1513-1514. [CrossRef]

24. Furusawa, M.; Hashimoto, T.; Noma, Y.; Asakawa, Y. Biotransformation of citrus aromatics nootkatone and valencene by mi-croorganisms. Chem. Pharm. Bull. 2005, 53, 1423-1429. [CrossRef]

25. Asakawa, Y.; Hashimoto, T.; Noma, Y.; Furusawa, M. Modification of Valencene by Bio- and Chemical Transformation. Nat. Prod. Commun. 2013, 8, 859-862. [CrossRef]

26. Serra, $\mathrm{S} . \mathrm{MnO}_{2}$ /TBHP: A versatile and user-friendly combination of reagents for the oxidation of allylic and benzylic methylene functional groups. Eur. J. Org. Chem. 2015, 29, 6472-6478. [CrossRef]

27. Tu, V.A.; Kaga, A.; Gericke, K.-H.; Watanabe, N.; Narumi, T.; Toda, M.; Brueckner, B.; Baldermann, S.; Mase, N. Synthesis and Characterization of Quantum Dot Nanoparticles Bound to the Plant Volatile Precursor of Hydroxy-apo-10'-carotenal. J. Org. Chem. 2014, 79, 6808-6815. [CrossRef]

28. Murray-Gulde, C.L.; Heatley, J.E.; Schwartzman, A.L.; Rodgers, J.J.H. Algicidal Effectiveness of Clearigate, Cutrine-Plus, and Copper Sulfate and Margins of Safety Associated with Their Use. Arch. Environ. Contam. Toxicol. 2002, 43, 19-27. [CrossRef] [PubMed]

29. Subashchandrabose, S.R.; Ramakrishnan, B.; Megharaj, M.; Venkateswarlu, K.; Naidu, R. Mixotrophic cyanobacteria and microalgae as distinctive biological agents for organic pollutant degradation. Environ. Int. 2013, 51, 59-72. [CrossRef] [PubMed]

30. Görs, M.; Schumann, R.; Hepperle, D.; Karsten, U. Quality analysis of commercial Chlorella products used as dietary supplement in human nutrition. Environ. Boil. Fishes 2009, 22, 265-276. [CrossRef]

31. Rzymski, P.; Jaśkiewicz, M. Microalgal food supplements from the perspective of Polish consumers: Patterns of use, adverse events, and beneficial effects. Environ. Boil. Fishes 2017, 29, 1841-1850. [CrossRef] [PubMed]

32. Yuan, J.-P.; Chen, F.; Liu, X.; Li, X.-Z. Carotenoid composition in the green microalga Chlorococcum. Food Chem. 2002, 76, 319-325. [CrossRef]

33. Zhang, D.-H.; Lee, Y.-K. Ketocarotenoid production by a mutant of Chlorococcum sp. in an outdoor tubular photobioreactor. Biotechnol. Lett. 1999, 21, 7-10. [CrossRef]

34. Liu, B.-H.; Lee, Y.-K. Composition and biosynthetic pathways of carotenoids in the astaxanthin-producing green alga Chloro-coccum sp. Biotechnol. Lett. 1999, 21, 1007-1010. [CrossRef]

35. Da Luz, D.S.; Da Silva, D.G.; Souza, M.M.; Giroldo, D.; Martins, C.D.M.G. Efficiency of neutral red, E vans Blue and MTT to assess vi-ability of the freshwater microalgae Desmodesmus communis and Pediastrum boryanum. Phycol. Res. 2016, 64, 56-60. [CrossRef]

36. Berridge, M.V.; Herst, P.M.; Tan, A.S. Tetrazolium dyes as tools in cell biology: New insights into their cellular reduction. Biotechnol. Annu. Rev. 2005, 11, 127-152. [CrossRef] [PubMed]

37. Wilson, C.W., II; Shaw, P.E. Synthesis of nootkatone from valencene. J. Agr. Food Chem. 1978, 26, 1430-1432. [CrossRef]

38. Hong, B.; Lebeuf, R.; Delbaere, S.; Alsters, P.L.; Nardello-Rataj, V. One-Pot Synthesis of (+)-Nootkatone via Dark Singlet Oxygenation of Valencene: The Triple Role of the Amphiphilic Molybdate Catalyst. Catalysts 2016, 6, 184. [CrossRef]

39. Prein, M.; Adam, W. The schenck ene reaction: Diastereoselective oxyfunctionalization with singlet oxygen in synthetic applications. Angew. Chem. Int. Ed. Engl. 1996, 35, 477-494. [CrossRef] 